Pediat. Res. 2: 519-524 (1968)

Acidosis propionic acid

hereditary disease propionyl coenzyme

liver, fatty A carboxylase

metabolic disease

\title{
Propionicacidemia, a New Inborn Error of Metabolism
}

\author{
F.A. Hommes, J.R. G. Kuipers, J.D. Elema, J.F.JAnsen and J.H.P. Jonxis ${ }^{[1]}$ \\ Departments of Pediatrics and Pathology, University of Groningen School of Medicine, Groningen, \\ and Department of Pediatrics, Bethesda Hospital, Hoogeveen, The Netherlands
}

\section{Extract}

A male sibling who was born of healthy parents and who died at the age of five days with the clinical picture of severe hypotonia, areflexia, hyperventilation, and grunting is described. An older female sibling with identical symptoms had died some years previously. The parents were unrelated and had three other healthy children. The patient exhibited severe metabolic acidosis which was resistant to therapy. This acidosis was caused by the presence in blood of propionic acid in a very high concentration $(5.4 \mathrm{mM} / \mathrm{l})$. The high levels of urea and potassium also present were probably the result of a markedly reduced urine production caused by dehydration. The levels of amino acid in plasma revealed low values for one amino acid, normal values for other amino acids, and high values for lysine, histidine, valine, isoleucine, and leucine.

At autopsy, except for a right descending aortic arch, no gross anomalies were found, although the liver was enlarged, probably because of increased fat content. Microscopic examination showed a fatty degeneration of liver cells, degeneration of the Purkinje cells and the granular layer in the cerebellum, and macrophages containing debris of blood cells in the bone marrow and in the spleen. Gas chromatography was used to determine the nature of the accumulated fat in the liver. Among the normal constituents of liver triglycerides, three abnormal fractions were observed, two of which contained $\mathrm{C}_{15}$ and $\mathrm{C}_{17}$ straight chain fatty acids. These were not observed in normal liver fat. The combination of propionicacidemia and the storage of fatty acids with an uneven chain number in the liver pointed to a block in the conversion of propionic acid into methylmalonic acid.

\section{Speculation}

It is suggested that the propionicacidemia found in this patient is due to a metabolic block in the conversion of propionic acid into methylmalonic acid. The increased concentration of odd-numbered fatty acids $\left(\mathrm{C}_{15}\right.$ and $\left.\mathrm{C}_{17}\right)$ in the liver may arise from either a decreased breakdown of these fatty acids or an increased synthesis initiated by the high concentration of propionyl-CoA. It is proposed that the missing enzyme is propionyl coenzyme A carboxylase. The fact that a sibling with identical symptoms had died forms a strong argument to postulate that a hereditary abnormality of recessive inheritance is the cause of this as yet undescribed syndrome. 


\section{Introduction}

Some inborn errors of metabolism are so severe that the mortality rate of affected children in the first weeks of life is very high. Maple sugar disease and one form of hyperglycinemia belong to this group. In the family reported here, two infants with identical clinical pictures died in the first week of life. We identified a possible cause of the metabolic disturbance in this family. The most striking finding was a severe metabolic acidosis which was difficult to correct with administration of alkali and was caused by the accumulation of large amounts of propionic acid in blood. An autopsy revealed an enlarged fatty liver. In the liver fat, uneven chain fatty acids were detected. These findings suggested that in the child reported in this study, the break-down of fatty acids with an uneven chain number was blocked at a level between propionic acid and the next metabolic product. The family history suggested that this abnormality was hereditary and that the condition hyperpropionicacidemia may be added to that group of inborn errors of metabolism which cause death in early childhood.

\section{Case Report}

The propositus, a boy, was the fourth child of unrelated parents. Another child, a girl with identical symptoms, died at the age of three days. The parents and the three other children were healthy. Birth was normal and the child cried spontaneously; birth weight was $3700 \mathrm{~g}$. At 60 hours of age, the patient was admitted to the Pediatric Clinic of the University Hospital and appeared to be a well-developed child. There was no cyanosis, but the child was hyperventilating and grunting. There was marked muscular hypotonia. Reflexes were hardly present. Table I summarizes the most important chemical data. Hematological examination revealed a leukocyte count of 10,900 (polymorphonuclear cells, $77 \%$; lymphocytes, $23 \%$ ); hemoglobin concentration, $21.2 \mathrm{~g} / 100 \mathrm{ml}$; and hematocrit, $66 \%$. The severe metabolic acidosis treated by intravenous administration of THAM and bicarbonate improved only temporarily. The low levels of calcium in blood were treated with administration of calcium levulinate. The total amount of fluid was restricted to $220 \mathrm{ml} / 24$ hours. The very limited production of urine, together with the breakdown of tissue, caused a rise in the levels of urea and potassium in blood. At the age of 104 hours the child died. The clinical symptoms remained unchanged during the time of observation.

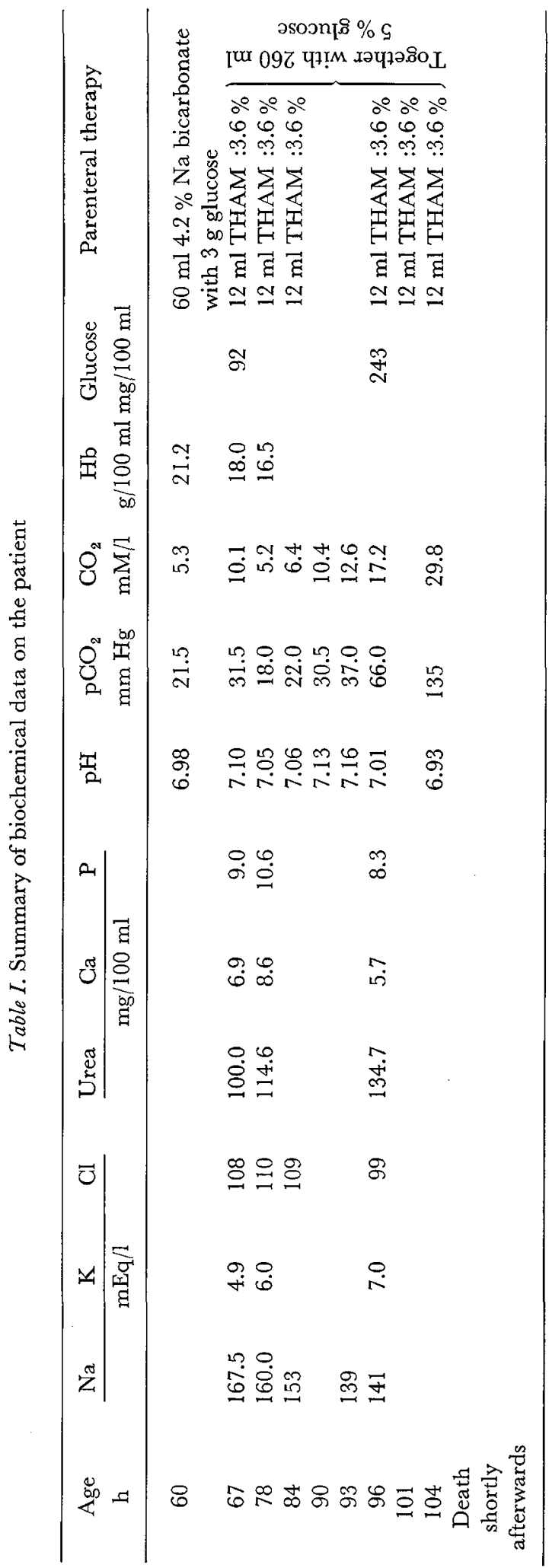




\section{Autopsy Findings}

Except for a right descending aortic arch, no anatomical malformations were found. The liver was enlarged. Microscopic examination revealed anomalies only in the liver, brain, spleen and bone marrow. The liver showed signs of a severe fatty degeneration. There was degeneration of the Purkinje cells and the granular layer in the cerebellum. Macrophages containing debris of blood cells were present in the spleen and bone marrow in increased amounts. The kidney showed neither macroscopical nor microscopical abnormalities.

\section{Methods}

Amino acids in blood plasma were analyzed by the method of MOORE and STEIN [5] using an automatic Spinco-Beckman Amino Acid Analyzer, model 120B. Plasma was deproteinized with picric acid [5]. Keto acids of plasma and urine were estimated by the methods of NATELSON [6]. The method of HoHorst [1] was used for the quantitative determination of lactate and pyruvate in blood.

Short chain fatty acids of blood plasma were identified by gas chromatography using the method of TANAKA et al. [9]. The positions of the acids in the chromatograms were substantiated with authentic samples.

Free fatty acids and triglycerides of the liver were analyzed by gas chromatography. Specimens of livers stored in formaldehyde were homogenized in a glass, Potter-Elvejhem, homogenizer and repeatedly extracted with chloroform-methanol $(1: 1)$. The extract was washed twice with distilled water, dried over $\mathrm{Na}_{2} \mathrm{SO}_{4}$, and evaporated to dryness. The fatty acids and triglycerides were converted to methyl esters by the method of Metcalfe et al. [4]. Gas chromatography of the methyl esters of the fatty acids was performed according the method of LrPsky et al. [2]. The position of the methyl esters in the chromatograms was checked with authentic samples [10].

Table II. Concentration of amino acids in plasma and urine of patient

\begin{tabular}{|c|c|c|c|c|}
\hline & Urine & $\begin{array}{c}\text { Plasma } \\
\text { age: } 70 \mathrm{~h}\end{array}$ & \multicolumn{2}{|c|}{$\begin{array}{c}\text { Normal plasma controls } \\
\text { (0-1 month, } 6 \text { cases }) \\
\text { nonfasting }\end{array}$} \\
\hline & \multicolumn{4}{|c|}{$\mu \mathrm{mol} / \mathrm{ml}$} \\
\hline & & & Mean & $\pm \mathrm{SD}$ \\
\hline Lysine & 0.18 & 1.33 & 0.10 & 0.10 \\
\hline Histidine & - & 0.18 & 0.04 & 0.02 \\
\hline Arginine & 一 & 0.01 & 0.02 & 0.02 \\
\hline Tryptophane & 0.20 & - & - & - \\
\hline Aspartic acid & - & - & 0.04 & 0.02 \\
\hline Threonine & 0.06 & 0.15 & 0.17 & 0.07 \\
\hline Serine & 0.23 & 0.81 & 0.74 & 0.32 \\
\hline Glutamic acid & - & 0.07 & 0.19 & 0.09 \\
\hline Proline & - & 0.40 & 0.43 & 0.22 \\
\hline Glycine & 0.44 & 0.58 & 0.42 & 0.22 \\
\hline Alanine & - & 0.13 & 0.45 & 0.21 \\
\hline Half cystine & - & - & 0.03 & 0.03 \\
\hline Valine & 0.18 & 0.87 & 0.25 & 0.13 \\
\hline Methionine & - & 0.02 & 0.01 & 0.01 \\
\hline Isoleucine & 0.07 & 0.40 & 0.12 & 0.07 \\
\hline Leucine & 0.12 & 0.64 & 0.14 & 0.07 \\
\hline Tyrosine & - & 0.35 & 0.12 & 0.12 \\
\hline Phenylalanine & 一 & 0.10 & 0.09 & 0.04 \\
\hline Total & 1.57 & 6.04 & 3.36 & 0.39 \\
\hline
\end{tabular}




\section{Results}

The analyses of amino acid in blood plasma and urine are summarized in table II. There were marked differences in the levels of amino acid in plasma in our patient compared with those of control subjects.

Concentrations of lysine, histidine, valine, isoleucine, leucine and tyrosine were elevated while that of alanine was significantly reduced. The initially high concentrations of hemoglobin and of sodium were caused by dehydration. Administration of $\mathrm{NaHCO}_{3}$ brought about a further rise in the level of sodium.

Pyruvate and lactate concentrations in blood were within normal ranges, 0.3 and $9.3 \mathrm{mg} / 100 \mathrm{ml}$ respec- tively. The level of keto acids was $0.15 \mu$ moles $/ \mathrm{ml}$ plasma. A mixture of plasma from 35 healthy donors gave a value of $0.10 \mu$ moles of keto acids $/ \mathrm{ml}$.

An isovaleric acidemia has been discovered recently by TANAKA et al. [9]. Their method was applied to the serum of our patient to determine whether he was suffering from this abnormality. The result is shown in figure 1. Figure 1A demonstrates that in normal control serum at this sensitivity, minimal levels of free short chain fatty acids can be detected. In the serum of our patient, isovaleric acid was absent. In the gas chromatogram, however, a large peak coinciding with that of added propionic acid was found (fig. 1B). Recovery of propionic acid was estimated by adding a

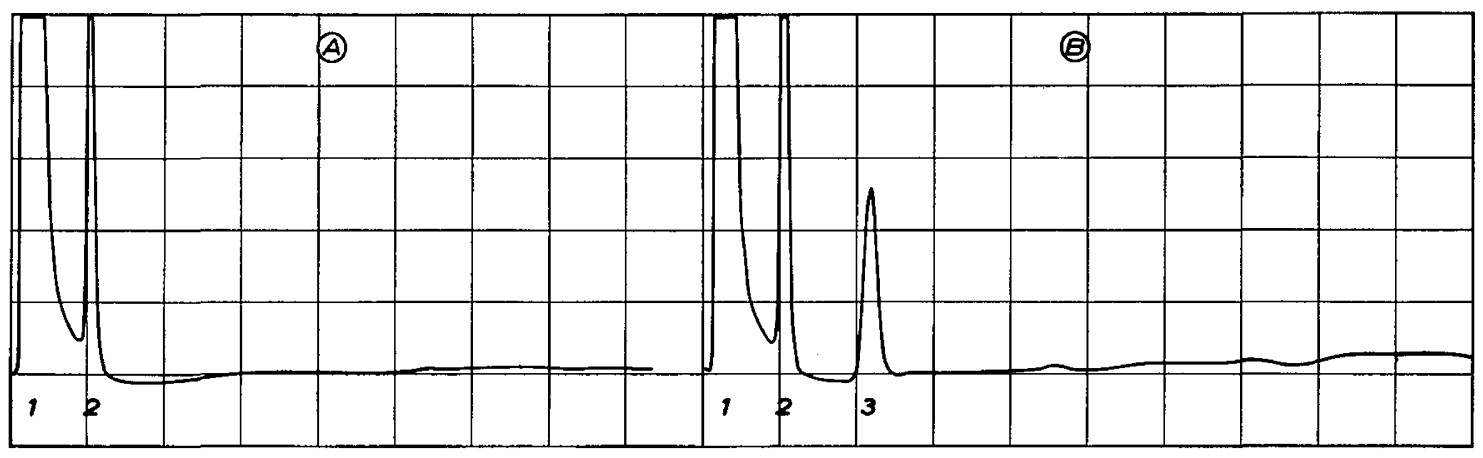

Fig. 1. Gas chromatograms of short-chain fatty acids of serum. The column was a 5 feet, 5 mm diameter glass column packed with Gaschrom P (100-120 mesh) coated with 25\% neopentylglycol adipate-2\% ortho phosphoric acid. Temperature $115^{\circ}$; inlet pressure 38 psi. A: Normal control serum; B: patient's serum; 1 : solvent; 2: formic acid; 3 : propionic acid.
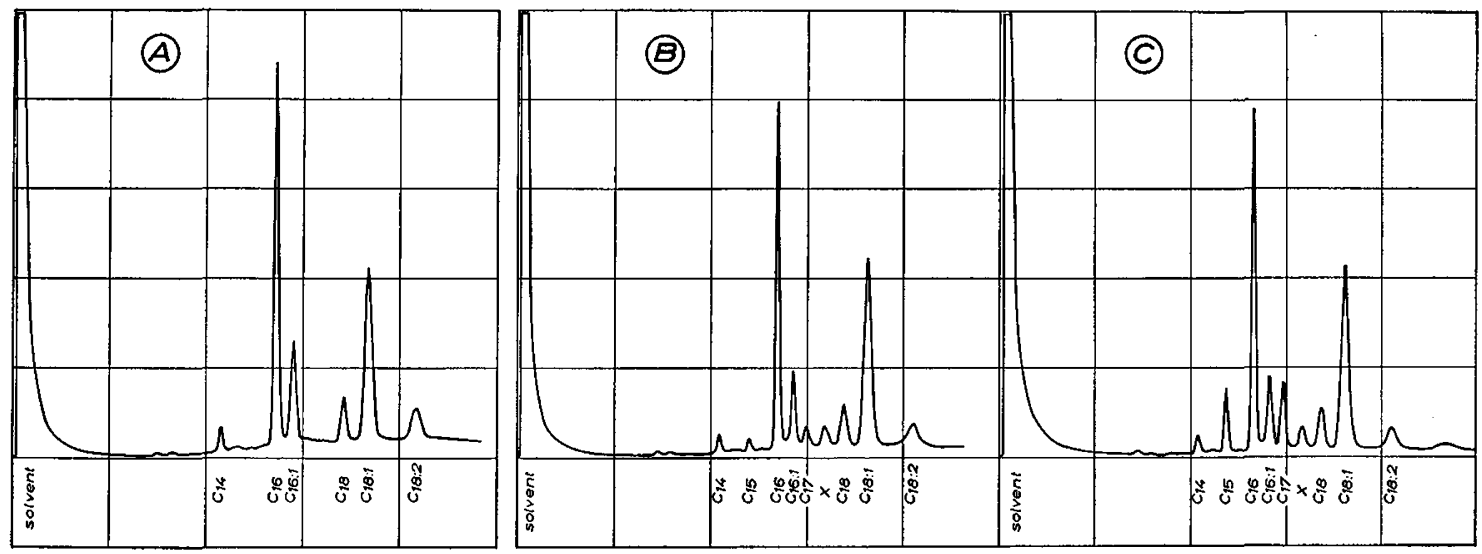

Fig. 2. Gas chromatograms of methyl esters of fatty acids extracted from liver. The column was a $6 \frac{1}{2}$ feet, $2 \mathrm{~mm}$ diameter stainless steel column packed with dietyleneglycol succinate, 6\% on Gaschrom P (100-120 mesh). Temperature from $100^{\circ}$ to $175^{\circ}$, programmed for an increase of 2 and $4^{\circ}$ per min. Inlet pressure: 38 psi. Gasflow: $60 \mathrm{ml}$ per h. A: Fatty acids of control liver; B: fatty acids of patient liver; C: fatty acids of patient liver, with added methyl esters of $\mathrm{C}_{15}$ and $\mathrm{C}_{17}$ fatty acid. 
known amount of propionic acid to normal serum and measuring the peak area. It could be calculated that the concentration of propionic acid in the patient's serum was about $40,000 \mu \mathrm{g} / 100 \mathrm{ml}$, which is $5.4 \mathrm{mM}$ propionic acid. TANAKA et al. [9] reported in children a normal value of $28 \mu \mathrm{g}$ propionic acid/100 $\mathrm{ml}$. The magnitude of the concentration of propionic acid in serum explains the low $\mathrm{pH}$ observed in the propositus. Since the patient had received multiple infusions of THAM and the conditions for extraction of shortchain fatty acids were somewhat drastic, the effect of THAM on the propionic acid peak observed in the gas chromatogram was investigated. THAM, up to a concentration of $3.5 \mathrm{mM}$, was added to a sample of serum from a control subject. No propionic acid was observed by gas chromatography when this serum was analyzed by the same procedure as that used for the serum of the patient.

One of the biosynthetic routes by which propionic acid is formed is the oxidative breakdown of oddnumbered fatty acids. It is conceivable that this metabolic route is inhibited by high concentrations of propionic acid; this would result in increased storage of fat containing both even- and odd-numbered fatty acids. A high concentration of propionic acid may also give rise to a replacement of acetyl-CoA by propionylCoA as a primer in fatty acid biosynthesis. That propionyl-CoA can act as a primer in this biosynthetic route has been shown by LyNen et al. [3]. The result will be production of odd-numbered fatty acids. Conditions proposed by either hypothesis would lead to an increased concentration of fatty acid with uneven chain number. To test these hypotheses, free fatty acid and triglyceride content were examined in portions of the liver obtained postmortem. Figure 2 gives the result of this analysis. Figure $2 \mathrm{~A}$ shows a gas chromatogram of the methyl esters of fatty acids obtained from a control infant of the same age whose liver had been stored in formaldehyde, just as was the liver of the patient. Figure 2B gives the results of the analysis of the patient's liver. In figure $2 \mathrm{~B}$, as compared with figure $2 \mathrm{~A}$, three additional peaks were observed. Two of them could be identified as the methyl esters of $\mathrm{C}_{15}$ and $\mathrm{C}_{17}$ fatty acids. Addition of known methyl esters of these acids confirmed the chemical nature of the peaks (fig. 20). The identity of the third peak remains unknown.

\section{Discussion}

Recently, OBERHOLzer et al. [7] described an inborn metabolic error, methylmalonic aciduria, in which acidosis was comparable to that seen in our patient. The metabolic block proposed was at the step in fatty acid metabolism just following propionic acid. The ketosis found in methylmalonic aciduria was not present in our patient. In comparison with our patient, the clinical symptoms in methylmalonic aciduria are less severe and the lifespan is longer.

The clinical and biochemical observations made in our patient demonstrate four prominent abnormalities: (1) hypotonia and areflexia; (2) high values of sodium, potassium, and urea in blood; (3) elevated levels of lysine, valine, isoleucine, and tyrosine in plasma; and (4) extremely high values for propionic acid in plasma. This last abnormality affords an explanation for the observed severe acidosis and was probably the main cause of circulatory failure and ultimately of death.

The metabolism of propionic acid is schematically shown in figure 3. Propionic acid (its CoA derivative) can be formed by oxidation of odd-numbered fatty acids or of the amino acids methionine, isoleucine and valine. By fixation of carbon dioxide, propionic acid is converted by the enzyme propionyl-CoA carboxylase to methylmalonyl-CoA, which is subsequently isomerized to succinyl-CoA. Succinyl-GoA enters the Krebs cycle and is further metabolized. Accumulation of propionic acid, as observed in this study, is likely to be the result of decreased activity of propionyl-CoA carboxylase. The failure to metabolize propionic acid at normal rates is probably the reason that the patient's metabolic acidosis could not be corrected by sodium bi-

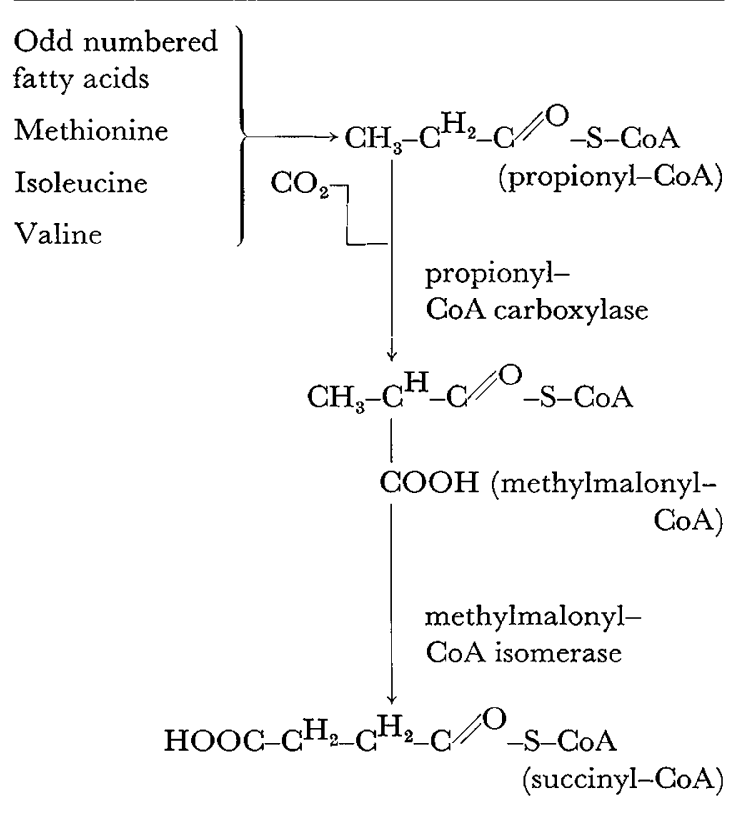

Fig.3. Metabolism of propionic acid. 
carbonate or by THAM. It is difficult to explain the abnormal concentration of some amino acids in the serum: the low values for alanine and the high values for valine, isoleucine, leucine, lysine and histidine.

In severe acidosis with low urine production, one might expect amino acid levels in plasma to be high. In our case, however, the rise was restricted to a limited number of amino acids, the values of others being normal and that of alanine being low. Another explanation might be that methionine, isoleucine, and valine can be converted into propionic acid and that the blocked conversion of propionic acid into methylmalonate secondarily caused a rise in these three amino acids. This explanation, however, does not explain the high levels of leucine, lysine, and histidine in plasma.

Except for a right-descending aortic arch, autopsy findings did not reveal any congenital anatomic abnormality. The cellular degeneration found in some tissues is probably the result of the metabolic disturbance, especially the severe acidosis. Of special importance is the degeneration of the Purkinje cells in the cerebellum and of macrophages in the bone marrow and in the spleen.

The death of an older sibling with identical symptoms at the same age is a strong argument in support of the hypothesis that the hyperpropionicacidemia in the infant described is an inborn error of metabolism. As no enzyme studies were possible, the exact nature of the enzymatic defect remains to be proved. It is probable, however, that the activity of propionyl coenzyme A carboxylase was abnormal.

\section{Summary}

The history of a child with propionicacidemia is reported. The child died at the age of five days; during life he exhibited severe hypotonia, areflexia, and a metabolic acidosis caused by the presence in blood of propionic acid at levels of $5.4 \mathrm{mM} / 1$. Postmortem examination showed fatty degeneration of the liver, degeneration of the Purkinje cells in the cerebellum, and macrophages in the bone marrow and in the spleen. Hepatic fat contained an increased amount of $\mathrm{C}_{15}$ and $\mathrm{C}_{17}$ saturated fatty acids, probably the result of a disturbance in the utilization of these fatty acids at the level of propionic acid.

The parents of the child were unrelated. In addition to three normal children, another sibling with identical symptoms had died at the same age. This family history suggests that propionicacidemia is due to an inborn error of metabolism with a recessive mode of inheritance.

\section{References and Notes}

1. Hohorst, H.J.: L(+)-lactate, determination with lactic dehydrogenase and DPN; in Methods of enzymatic analysis (ed. Bergmerjer, H.U.), 2nd ed., p. 266 (Academic Press, New York 1965).

2. Lipsky, S.R.; Landown, R.A. and Godet, M.R.: The effects of varying the chemical composition of the stationary liquid on the resolution of the long chain saturated and unsaturated fatty acids by gas liquid chromatography. Biochim. biophys. Acta 31: 336 (1959).

3. Lynen, F.; Hopper-Kessel, I. und Eggerer, H.: Zur Biochemie der Fettsäure. III. Die Fettsäuresynthese der Hefe und die Bildung enzymgebundener Acetessigsäure. Biochem. Z. 340: 95 (1964).

4. Metcalfe, L.D.; Smitz, A.A. and Pelka, J.R.P.: Preparation of methyl esters from triglycerides and other lipids. Anal. Chem. 38: 514 (1966).

5. Moore, S. and Stein, W.H.: A modified ninhydrinre agent for the photometric determination of amino acids and related compounds. J.biol. Chem. 211: 907 (1954).

6. Natelson, S. : Microtechniques of clinical chemistry for the routine laboratory (Thomas, Springfield, Ill. 1957).

7. Oberholzer, V.G.; Levin, B.; Burgess, E. and Young, W.F.: Methylmalonic aciduria: An inborn error of metabolism leading to chronic metabolic acidosis. Arch. Dis. Childh. 42: 492 (1967).

8. Stern, W.H. and Moore, S.: The free amino acids of human blood plasma. J.biol. Chem. 211: 915 (1954).

9. TANaka, K.; Budd, M.A.; Efron, M. L. and IsselBACHER, K.J.: Isovaleric aciduria: A new genetic defect of leucine metabolism. Proc. nat. Acad.Sci., Wash. 56: 236 (1966).

10. We express our thanks to Dr. W.J.E. Voer of Unilever Research Laboratory, Vlaardingen, The Netherlands, for a gift of the $\mathrm{C}_{15}$ acid.

11. Requests for reprints should be addressed to: J.H.P. Jonxis, M.D., Department of Paediatrics, State University, 59 Oostersingel, Groningen (The Netherlands). 